\title{
The studies on the production of polylactide's paper adhesive
}

\author{
Tomasz M. Majka *1, Agnieszka Świętoń ${ }^{1}$ \\ 1 Tomasz M. Majka Cracow University of Technology, Department of chemistry and technology of polymers, \\ Warszawska 24, 31155 Cracow Poland; tomasz.majka@pk.edu.pl \\ 1 Agnieszka Świętoń Cracow University of Technology, Department of chemistry and technology of \\ polymers, Warszawska 24, 31155 Cracow Poland; piotr.stachak@gmail.com \\ * Correspondence: tomasz.majka@pk.edu.pl; Tel.: +48-500-567-355
}

Received: 24/10/2017

\begin{abstract}
The process of bonding and adhesives are an important part of human life from the earliest times. Over the years, a development has evolved. Natural adhesives were increasingly replaced by synthetic, which allowed to obtain more permanent weld and glue together different types of materials. Despite the emergence of new industrial sectors which allowed to connect components such as soldering, welding, thermal bonding, rivets, screws or pins gluing process did not lose in significance. People are willing to use the features and ease of use adhesives. Ecological aspects, however, pay attention to the safety of the environment. Decreasing non-renewable sources and the growing amount of waste affects the market, on which to a greater extent firms appear with environmentally friendly technologies. An important field of biodegradable polymers are produced from renewable raw materials that do not affect negatively the environment. Nowadays, more and more research is conducted to increase the scope of their use. This thesis presents a method to prepare polylactide paper adhesives and the effects of additives on its properties. This review shows a lack of studies on polylactide adhesives in the literature. This led to a series of experimental studies related to the selection of appropriate adhesive formulations, as well as additives favorably affecting the strength of the glued joints. The object of the study were the four compositions with the same concentration (polylactide dissolved in chloroform - primary composition, the composition containing pigments, the composition containing the essential oil and the composition with corn flour). The resulting compositions were subjected to a series of experimental studies peel strength. The lifetime of adhesives were determined, and we finally propose a method and the respective conditions for their long-term storage.
\end{abstract}

Keywords: paper adhesive, polylactide, mechanical properties. 


\section{Introduction}

At present there are a wide range of natural adhesives, but since the twentieth century they are largely supplanted by synthetic adhesives. Among these types of adhesives there is also a wide choice. We specialize in adhesives for wood, metal, paper, textiles and plastics. Adequately selected glue allows for high strength glued joints under various operating conditions. Over time, the impact on the industry and the direction of innovative programs has a non-economic and ecological aspect. The environmental constraints imposed on most plastics from non-renewable sources such as oil, natural gas and hard coal, and the enormous amount of waste all change the way people think about environmental safety.

More and more companies are emerging on the market with environmentally friendly technologies. The importance of biodegradable polymers also increases. They play a significant role in medicine, but also in agriculture, horticulture and the packaging industry. Biodegradable plastics break down into naturally occurring substances in the environment, relatively quickly and without the release of harmful substances [1].

Taking into account the above mentioned factors such as the development of industry, the reduction of non-renewable sources, the increase of plastic waste, the increasing importance of biodegradable polymers as well as the increasing demands of consumers, the need to produce new adhesive is emerging. An adhesive which will be non-toxic, biodegradable and will exhibit satisfactory bonding parameters.

\section{Materials and Methods}

\subsection{Materials used}

\subsubsection{Polylactide}

The Ingeo 3052D polylactide nature was purchased from Nature Works, based in Naarden, The Netherlands.3.1.2. Nanofiller

\subsubsection{Solvent}

The main solvent used to obtain the glue was chloroform purchased from Avantor Performance Materials Poland S.A. (POCH) based in Gliwice.

\subsubsection{Additives}

Red dye number A530.01 produced by Tudor Geum, Kingfisher Colors Ltd., based in Berkshire, $\mathrm{UK}$;

Eucalyptus essential oil produced by PPHU KEJ Sp. with o.o. in Wieliczka

Maize meal produced by Janex company in Janów Lubelski

\subsection{Solvent selection and glue composition}

Attempts to dissolve the polylactide in various solvents (Table 1). For this purpose, a MS 11 magnetic stirrer was used. All test solutions were prepared with the same concentration $(10 \%)$.

Dissolution experiments were carried out in solvents at room temperature as well as at their boiling point. In most trials, the polylactide did not dissolve and, as the temperature increased, melted. Studies with formic acid and xylene ended with a good result, but after a few hours the solutions were delaminated. Best results were obtained using chloroform, which provided adequate homogeneity of the solution. The process was stirred with heating, but the same end effect was achieved by leaving PLA with chloroform in a sealed container at room temperature $\left(20^{\circ} \mathrm{C}\right)$ for several hours. The problem of dissolving polylactide in a wide range of organic solvents used was related to the type of polymer used. The purchased polymer was poly (L-lactide) containing one kind of L (-) isomers. Poly (L-lactide) tends to dissolve in similar solvents having also one type of 
isomer. In this way it is possible to explain the ease of dissolution in chloroform and other chlorine-containing organic solvents, as well as furan, dioxane or pyridine. The use of poly(D, L-lactide) could result in its dissolution in bio-solvents such as, for example, ethyl lactate [2].

Table 1. Examples of solvents used and results of the dissolution process of PLA

\begin{tabular}{cc}
\hline Solvent & PLA \\
\hline Castor oil & Insoluble \\
Citric acid + salicylic spirit & Insoluble \\
Vitamin A & Insoluble \\
Vitamin B5 & Insoluble \\
Vitamin C & Insoluble \\
Vitamin E & Insoluble \\
Lactic acid & Insoluble \\
Formic acid & Dissolves but delaminates \\
Chloroform & Soluble \\
Acetone & Insoluble \\
Glicerine & Insoluble \\
Ksylene & Dissolves but delaminates \\
\hline
\end{tabular}

After selecting the appropriate solvent, further tests were carried out to obtain optimum solution concentration, ie one in which the polylactide solution had a gel consistency and no undissolved polymer particles were observed. In the next step, the remaining adhesive additives were selected.

All the compositions were prepared by dissolving PLA in chloroform to give a $10 \%$ solution. Each of the solutions prepared had a total weight of $500 \mathrm{~g}$. The composition of the individual compositions is shown in Table 2.

In the case of additives such as dye and essential oil, they were first mixed with the solvent and then with the polylactide for better homogenisation. Using corn flour, a portion of the solvent was added to the polylactide, and the flour portion, after a few hours, was thoroughly mixed and then combined to give a uniform solvent glue.

Table 2. Composition of tested adhesives

\begin{tabular}{cccccc}
\hline Indication & \multicolumn{5}{c}{ Composition [g] } \\
\hline & PLA & Solvent & Dye & Essential oil & Maize meal \\
Composition 1 & 50.0 & 450.00 & - & - & - \\
Composition 2 & 50.0 & 449.95 & 0.05 & - & - \\
Composition 3 & 50.0 & 425.00 & - & 25.0 & - \\
Composition 4 & 50.0 & 375.00 & - & - & 75 \\
\hline
\end{tabular}




\subsection{The adhesive life}

The adhesive life of ASTM D 1338 determines the time elapsed since adhesive is ready for use until the composition is ready for use. The air drying time of the adhesive was measured at room temperature according to standard [3]. The same amount of glue was measured $(1 \mathrm{ml})$ and then glued evenly onto the surface of $2.5 \mathrm{~cm} \times 20 \mathrm{~cm}$ of paper and cardboard of different weights: $80 \mathrm{~g} / \mathrm{m}^{2}, 160 \mathrm{~g} / \mathrm{m}^{2}, 190 \mathrm{~g} / \mathrm{m}^{2}$ in the field. Time counting starts from the moment the adhesive is applied to a completely dry surface. The test was repeated min. 5 times and the results were averaged.

\subsection{Peel test - test at $180^{\circ}$}

Tensile strength was tested using the Zwick 1445 standard machine [4]. Tensile jaws with a propagation speed of $150 \mathrm{~mm} / \mathrm{min}$ were used. Test samples were prepared from office paper of different weights: $80 \mathrm{~g} / \mathrm{m}^{2}, 160 \mathrm{~g} / \mathrm{m}^{2}, 190 \mathrm{~g} / \mathrm{m}^{2}$. The samples were rectangular in size of $20 \mathrm{~cm} \times 2.5 \mathrm{~cm}$ and the glue surface was $6.5 \mathrm{~cm} \times 2.5 \mathrm{~cm}$. Each time, the same quantity of glue $(0.5 \mathrm{ml})$ was applied. Before attaching in the jaws, the adhesive was loaded with a weight of $5 \mathrm{~kg}$. A test for min. 5 samples of each material after the same time ie 2.5 minutes and 7.5 minutes.

\subsection{Impact test - tear off type $T$}

The test was carried out using the Zwick 1445 universal load testing device [5]. Application of tensile jaws at a speed of $500 \mathrm{~mm} / \mathrm{min}$. Prepared to the basket $20 \mathrm{~cm} \times 2.5 \mathrm{~cm}$ with weight: $80 \mathrm{~g} / \mathrm{m}^{2}$, $160 \mathrm{~g} / \mathrm{m}^{2}, 190 \mathrm{~g} / \mathrm{m}^{2}$. Surface glued pattern $13 \mathrm{~cm}$ x 2,5 cm. $1 \mathrm{ml}$ of glue was applied. Soft component glued to the hard component (cardboard). Before attaching in the jaws, the load carrying capacity of $5 \mathrm{~kg}$. A test for min. 5 samples of any kind of heavy and soft component after $7.5 \mathrm{~min}$.

\subsection{Storage of glue}

The study was conducted in two types of containers: polypropylene and aluminum. The adhesives were stored at room temperature, without sunlight. During the four months trial period, the adhesives and their binding properties were checked.

\section{Results and Discussion}

\subsection{The adhesive life}

The life span of the adhesive determines the time elapsed since the adhesive is ready for use until the composition is unusable. The results of the glue life measurement are shown in Table 3.

Table 3. Results of glue drying time for four compositions (Composition 1 - without additives, Composition 2 - with dye, Composition 3 - with Essential Oil, Composition 4 - with corn meal) for various substrates

Drying time of glue in the air $[\mathrm{s}]$

\begin{tabular}{lcccc}
\hline & Paper $80 \mathrm{~g} / \mathrm{m}^{2}$ & Paper $160 \mathrm{~g} / \mathrm{m}^{2}$ & Paper $190 \mathrm{~g} / \mathrm{m}^{2}$ & Cardboard \\
Composition 1 & 220 & 221 & 236 & 325 \\
Composition 2 & 293 & 210 & 222 & 324 \\
Composition 3 & 352 & 284 & 305 & 358 \\
Composition 4 & 453 & 335 & 338 & 465 \\
\hline
\end{tabular}

The results of the Basic Composition 1 test show that the drying time slightly increased with the increase in substrate thickness. The substrate type had little effect on the adhesive drying time, 
especially for $80 \mathrm{~g} / \mathrm{m}^{2}$ paper and $160 \mathrm{~g} / \mathrm{m}^{2}$ where there was almost no time difference. On the other hand, cardboard substrates required much longer time compared to paper with the smallest weight (105 seconds more). The dye addition increased the adhesive drying time on paper by $80 \mathrm{~g} / \mathrm{m}^{2}$, but on the other substrates the measurements were close to the results of Composition 1 without additive. The results of the composition measurement with essential oil are much greater than Composition 1. The biggest difference appeared on $80 \mathrm{~g} / \mathrm{m}^{2}$ paper (132 seconds). The addition of corn flour greatly influenced the drying time of the glue. Tested adhesives with additives showed that the drying process on $80 \mathrm{~g} / \mathrm{m}^{2}$ paper required more time than the $160 \mathrm{~g} / \mathrm{m}^{2}$ paper, and the basic composition showed a slight difference of $1 \mathrm{~s}$. For all compositions, the measurement time was extended in the order of paper on paper substrate weight $160 \mathrm{~g} / \mathrm{m}^{2}, 190 \mathrm{~g} / \mathrm{m}^{2}$, and also on cardboard substrate.

\subsection{Peel test - test at $180^{\circ}$}

In the topic of obtaining and testing adhesives, the strength of cohesion and adhesion is very important, as well as information on what materials are made of glue and how well glued surfaces fit together. In this study, the force was measured. Under the influence of which the weld was destroyed. The results are shown in Figure 1.
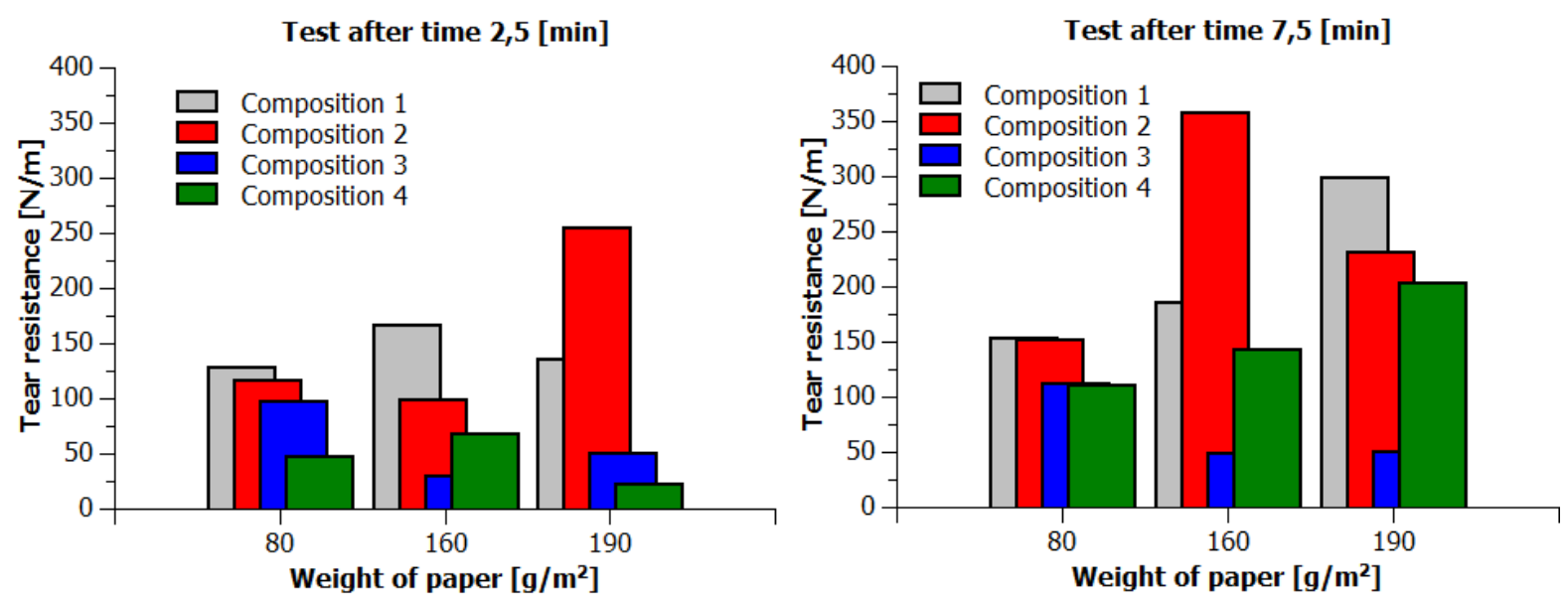

Figure 1. Tensile strength $(\mathrm{R})$ of $80 \mathrm{~g} / \mathrm{m}^{2}$ bonded substrate and $190 \mathrm{~g} / \mathrm{m}^{2}$ bonded with four polylactide adhesive compositions (Composition 1 - without additives, Composition 2 - with dye, Composition 3 -with Essential Oil, Composition 4 - with corn meal)

Results of the test after 2.5 minutes of gluing of the paper surface did not indicate a clear trend in paper weight. However, in the case of the maximum force required to peel the two surfaces together with the test glues on a basis weight basis of $80 \mathrm{~g} / \mathrm{m}^{2}$, a certain dependence can be observed. Highest durability showed a weld based on the basic composition (maximum peeling strength was about $125 \mathrm{~N} / \mathrm{m}$ ), followed by a dye composition $(115 \mathrm{~N} / \mathrm{m})$, a composition with essential oil (about $100 \mathrm{~N} / \mathrm{m}$ ). A significantly lower value was obtained with corn meal, is about $45 \mathrm{~N} / \mathrm{m}$. Wax produced on $160 \mathrm{~g} / \mathrm{m}^{2}$ by Compositions 1 and 4 proved to be stronger. For composition with dye, the cohesion strength decreased gently, resulting in a slight decrease in the value of peel strength. The highest difference in $R$ values compared to a paper weight of $80 \mathrm{~g} / \mathrm{m}^{2}$ was observed for the welds obtained using the essential oil composition. Comparing values of $R$ at $190 \mathrm{~g} / \mathrm{m}^{2}$, there were two main trends observed with respect to the $160 \mathrm{~g} / \mathrm{m}^{2}$ basis: Compositions 1 and 4 exhibited a very similar trend of changes in mechanical strength. On the other hand, the highest weld resistance on a substrate of $190 \mathrm{~g} / \mathrm{m}^{2}$ was found in Composition 2. The tests carried out after 7.5 minutes indicated more reproducible results, as they could see less scattering and some orientation. Increasing the thickness of the bonded paper resulted in an increase in the joint of the weld when applied to the base composition, maize meal composition, and dye composition. Although there was some deviation in Composition 2, the highest $\mathrm{R}$ value was obtained on $160 \mathrm{~g} / \mathrm{m}^{2}$ paper. A completely different 
character was shown by an ethereal adhesive, where the increase in thickness of the glued paper reduced the durability of the weld. In this case, there was also the smallest difference in the results obtained for the last two types of paper, only $1 \mathrm{~N} / \mathrm{m}$.

\subsection{Impact test - tear off type $T$}

The study measured the maximum peeling force of a weld of the appropriate width joining paper of different weights with cardboard, as well as cardboard carton. The results are shown in Figure 2.

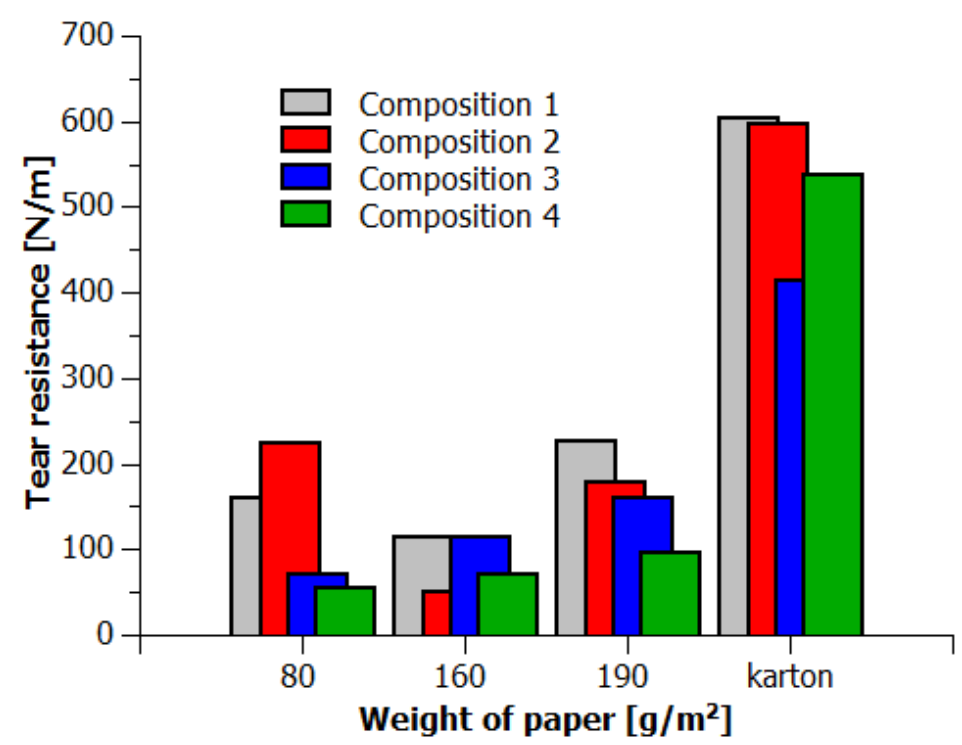

Figure 2. Tensile strength (T) of $80 \mathrm{~g} / \mathrm{m}^{2}, 160 \mathrm{~g} / \mathrm{m}^{2}, 190 \mathrm{~g} / \mathrm{m}^{2}$ and cardboard bonded with four adhesive compositions (Composition 1 - without additives, Composition 2 - with dye, Composition 3 -with Essential Oil,

Composition 4 - with corn meal)

Based on the results obtained, there were some indications. Increasing the thickness of the bonded paper resulted in an increase in the glued joint of the composition with the essential oil composition and corn meal composition. The use of the basic composition and the dye composition allowed the $80 \mathrm{~g} / \mathrm{m}^{2}$ welded substrate to exhibit the highest $\mathrm{T}$ values compared to the paper-card weld. Significant increase in joint was observed in all cardboard-carton glued joints regardless of the adhesive used. In this case, the cartons glued together with these compositions achieved several times the tear strength (the use of maize meal compositions made it possible to achieve up to 10 times higher $\mathrm{T}$ values compared to the result obtained for cardboard weld $80 \mathrm{~g} / \mathrm{m}^{2}$ ). The best adhesive properties showed the composition without additives and subsequently the composition with the dye. The use of the composition with essential oil resulted in higher $T$ values than the use of Compound 4 in cardboard glued joints. The opposite was the case in cardboard-cardboard glued joints, where better results were obtained with corn meal.

\subsection{Storage of glue}

Adhesive after 2 months the polypropylene packaging was not suitable for use. This was due to the leakage of the container, as the access of oxygen resulted in the drying of the adhesive. Aluminum packages have fulfilled their role, ensuring tightness and no evaporation of the solvent. Based on the studies, the storage condition of polylactide glue was determined. Keep the product in a dry and cool place. Optimal storage temperature is $+8^{\circ} \mathrm{C}$ to $+25^{\circ} \mathrm{C}$. Under such conditions, the adhesive life is between 2 and 4 months. Open container should be used within 3 weeks. Protect the packaging against low and high temperatures, as well as direct sunlight. 


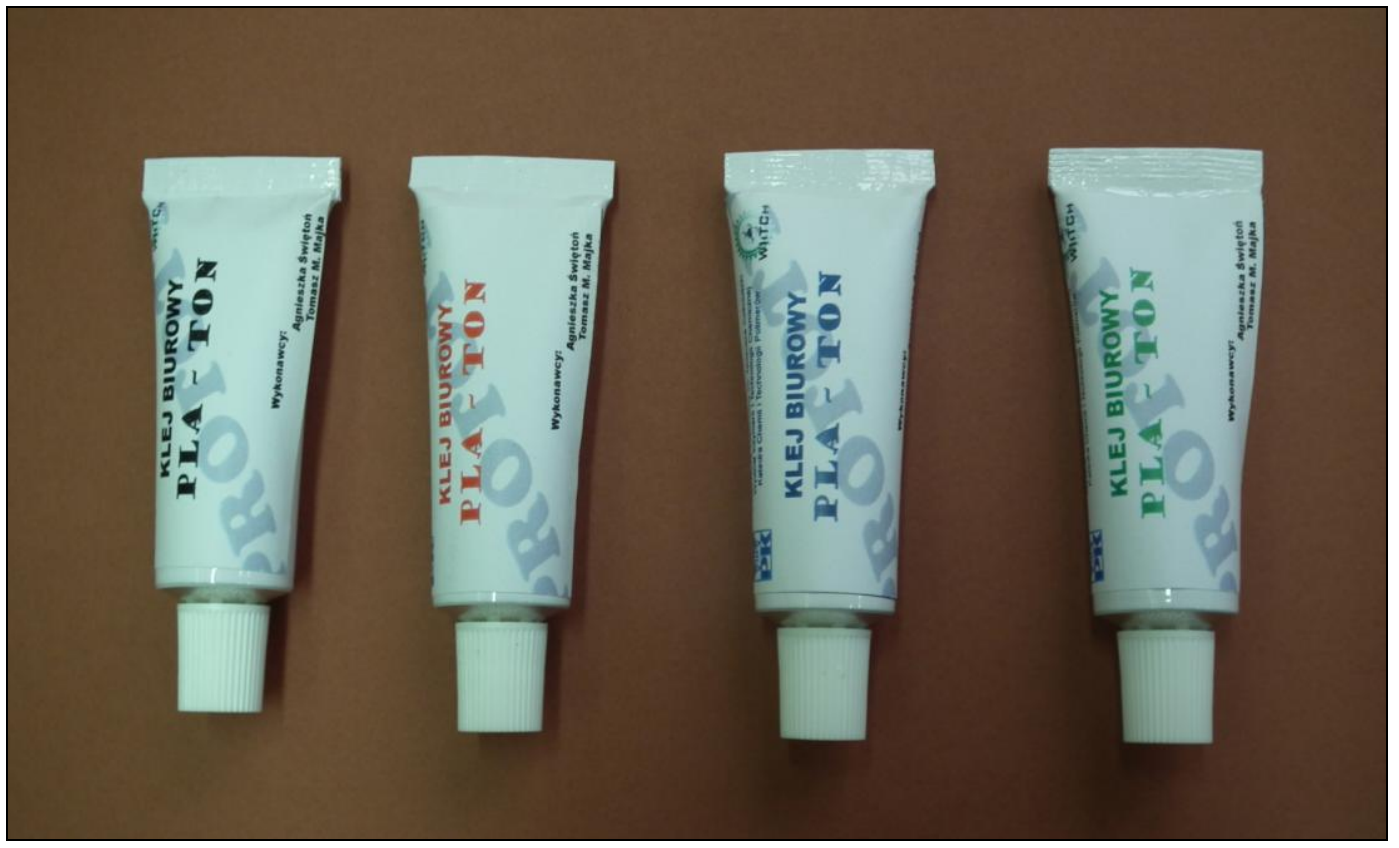

Figure 3. Polylactide glues obtained, packed in aluminum tubes

\section{Conclusions}

A series of experimental studies related to the choice of suitable adhesive formulation was made, as well as a selection of additives that would favor the strength of the bonded joint. Four adhesive formulations were obtained: base material (Composition 1), dye-containing adhesive (Composition 2), ethereal adhesive (Composition 3) and maize meal adhesive (Composition 4). The obtained compositions were subjected to a series of experimental studies. The life time of the adhesive was also determined, as well as the storage tests of the obtained adhesives and the proposed method and conditions for their long-term storage.

The air drying time of the composition was longer for measurements made on cardboard substrate than on paper substrate. This was due to the more porous structure of the carton. Its surface was easier to absorb with a polylactide solvent than paper with a smooth surface. The maize meal composition achieved the highest drying time as the additive used has hindered the process of spreading the adhesive so that the drying process did not occur simultaneously on the entire surface.

It is easy to see the effect of time on the durability of the bonded joint. By prioritizing the adhesive drying time, it is possible to select a suitable measurement time which is one of the test criteria. The results obtained 7.5 minutes from gluing of paper surfaces indicated some trends that could not be found in values received after a shorter time. Increasing the thickness of the bonded paper resulted in an increase in the glued joint of the weld when applied to the base composition, maize meal composition, and dye composition. A completely different character was shown by the composition with essential oil, where the increase in thickness of the glued paper reduced the durability of the weld. This may be due to too rapid absorption of glued substrates. For a $160 \mathrm{~g} / \mathrm{m}^{2}$ and $190 \mathrm{~g} / \mathrm{m}^{2}$ surface, where the difference in thickness is not high, similar tear strength values are obtained. The results of the impact strength measurement show that stronger bonding using the prepared adhesives is achieved by combining cardboard substrates than mixed paper-based substrates.

Attempts to store polylactide glue in polypropylene and aluminum containers at room temperature showed that the glue (regardless of composition) after 2 months of storage in polypropylene packaging was unsuitable. This is due, among other things. From the leak of the container, because the access of oxygen caused the adhesive to dry. Aluminum packages have fulfilled their role, ensuring tightness and no evaporation of the solvent. Based on the research, the conditions of storage of office polylactide adhesive were proposed. 
Author Contributions: Tomasz M. Majka. conceived and designed the experiments; Agnieszka Świętoń performed the experiments; Tomasz M. Majka and Agnieszka Świętoń analyzed the data; Agnieszka Świętoń wrote the paper.

Conflicts of Interest: The authors declare no conflict of interest. The founding sponsors had no role in the design of the study; in the collection, analyses, or interpretation of data; in the writing of the manuscript, and in the decision to publish the results.

\section{References}

1. Krzan A .; Biodegradable polymers and plastics; Innovative Value Chain Development for Sustainable Plastics in Central Europe (PLASTiCE), Poland, 2012; p. 2-8.

2. Gołębiewski J ; Gibas E .; Malinowski R .; Selected biodegradable polymers - preparation, properties, application; Polymers, Poland, 2008; No. 11-12, p. 799-805.

3. PN-ISO 10364:1999, Kleje - Oznaczenie czasu roboczego (żywotności) klejów wieloskładnikowych.

4. PN-EN ISO 851022010 U, Część 2: Oddzieranie pod kątem 180 stopni

5. PN-EN ISO 113392010 U, Kleje - Oznaczenie wytrzymałości na oddzieranie, metodą T, połączeń materiału giętkiego z giętkim

(C) 2017 by the authors. Submitted for possible open access publication under the terms and conditions of the Creative Commons Attribution (CC BY) license (http://creativecommons.org/licenses/by/4.0/). 